\title{
Patients' Level of Satisfaction with the Health Care Services Received at Outpatient Departments in Kilimanjaro Region, Tanzania
}

\section{Olomi GA ${ }^{1,3 *}$, Mboya IB ${ }^{1}$ and Manongi $\mathbf{R N}^{1,2}$}

${ }^{1}$ Community Health Department, Institute of Public Health, Kilimanjaro Christian Medical University College, Box 2240, Moshi, Tanzania

${ }^{2}$ Community Health Department, Kilimanjaro Christian Medical Centre, Box 3010, Moshi, Tanzania

${ }^{3}$ Reproductive and Child Health Department, Mawenzi Regional Referral Hospital, P.O Box 3054 Moshi, Tanzania

\begin{abstract}
Introduction: Patients' satisfaction is a measure of health system performance and can be used as a foundation of encouraging health care providers to become more responsible to their patients. Satisfaction manifests itself as a distribution, access and utilization of health services. This study aimed to determine patients' level of satisfaction with the health care services received in outpatient department in Kilimanjaro Region.
\end{abstract}

Methods: A cross-sectional study design was conducted at Mawenzi Regional Referral Hospital (MRRH), Same District Hospital (DH) and Huruma Designated District Hospital (DDH) using Donabedian model to determine patients' level of satisfaction with the health care services received at outpatient departments in Kilimanjaro Region. Systematic sampling was used to select 450 patients. Service quality questionnaire was used for data collection. Descriptive statistics was performed. Paired sample t-test, independent sample t-test and one-way ANOVA with Bonferroni posthoc test were used to compare mean gap scores. A p-value of $<0.05$ was considered statistically significant.

Results: The overall patient's level of satisfaction with health service provision at OPD in all three hospitals was $20 \%$. The gap on health services provision in all three hospitals was $-37.0( \pm 47.0)$ signifying overall dissatisfaction among patients. No statistically significant difference $(p<0.05)$ on the gap in satisfaction with quality of service provision existed between MRRH and Huruma DDH as well as between MRRH and Same DH. However, a significant gap difference was demonstrated between Huruma DDH and Same DH $(p, 0.002)$ with a smaller gap in satisfaction at Huruma DDH compared to Same DH (-28.0 versus -46.7$)$. The highest level of dissatisfaction in the five service dimensions tested was on empathy $(-7.8)$.

Conclusion: Patients attending OPD in all three hospitals demonstrate an overall dissatisfaction with quality of care. Hospital managements should focus on: improvement of patient-provider relationship, availability of equipment and drugs and affordability of hospital bills.

Keywords: Patients; Satisfactions; OPD services; Hospital; Tanzania

\section{Abbreviations}

DH: District Hospital; DDH: Designated District Hospital; MRRH: Mawenzi Referral Regional Hospital; OPD: Outpatients Department; SERVQUAL: Service Quality

\section{Introduction}

Traditionally, quality of health care services has been measured by means of professional standards ignoring the importance of patient's satisfaction [1,2]. The level of patients' satisfaction is important for improving the quality of care provided. Based on different studies, there is a high variation of patients' level of satisfaction between countries and within country.

In developed countries, patients are highly satisfied (90-95\%) with the basic services provided at outpatient departments (OPD, while in developing countries it has been shown that, the range of patients' satisfaction vary between $95 \%$ to $<50 \%$. In Nigeria $84 \%$ are satisfied while in Ethiopia $77 \%$ are satisfied with the health services rendered at the OPD [3-5]. In Tanzania, at Muhimbili National Hospital satisfaction level was found to be high (90\%-95\%) while in Morogoro (Kilosa District Hospital) satisfaction level was moderate (70\%) but at Mwananyamala Referral Hospital, satisfaction level was found to be low $(<50 \%)$ [6-8]. If patient's level of satisfaction on quality of care does not meet their standards, patients may decide to seek treatment somewhere else out of the formal health system that may lead to poor health seeking behaviors resulting in poor initial uptake of services, poor adherence, poor retention of services and at the end this may contribute to high morbidity and mortality.
OPD is a gateway to almost all of the hospital services whereby $80 \%$ of patients are attended at OPD globally [9]. Similarly about $80 \%$ of patients in Tanzanian hospitals are out-patients [10]. OPD services normally provide basic services to patients from registration in order to get a hospital file, consultations, laboratory, radiology and pharmacy services among others, but some of these services differ according to the different levels of health facilities.

There is no evidence that a similar study has been conducted in Kilimanjaro region located in the Northern zone of Tanzania to assess patient's level of satisfaction on the quality of health care delivery in different health facilities which is crucial for improving quality of health services rendered to patients. Based on variations in patients' level of satisfaction for instance between regions and hospitals in Tanzania,

*Corresponding author: Gaudensia Aloyce Olomi, Community Health Department Institute of Public Health, Kilimanjaro Christian Medical University College, Box 2240, Moshi, Tanzania, Reproductive and Child Health Department, Mawenz Regional Referral Hospital, P.O Box 3054 Moshi, Tanzania, Tel: 255756831210; E-mail: olomigaudensia@yahoo.com

Received December 01, 2016; Accepted December 19, 2016; Published December 27, 2016

Citation: Olomi GA, Mboya IB, Manongi RN (2017) Patients' Level of Satisfaction with the Health Care Services Received at Outpatient Departments in Kilimanjaro Region, Tanzania. J Pat Care 3: 124. doi: 10.4172/2573-4598.1000124

Copyright: $\odot 2016$ Olomi GA, et al. This is an open-access article distributed unde the terms of the Creative Commons Attribution License, which permits unrestricted use, distribution, and reproduction in any medium, provided the original author and source are credited. 
coupled with limited information from northern zone, this study aimed to determine patient's level of satisfaction with the health care services in Kilimanjaro Region. Findings from this study will recommend improvements of the services offered at the outpatient departments hence improve patients care.

\section{How to measure patients' satisfaction level}

According to different studies done worldwide, it is well documented that patient's level of satisfaction with the quality of health care services can be measured through its structure, process and outcome. Structure domain (tangibles and assurance) includes availability of hospital equipment including drugs, hospital cleanliness, staffing level and affordability of hospital services. Process domain (reliability, responsiveness and empathy) includes patient-provider relationship, confidentiality and waiting time [6,8,11-13].

In this study, patient's level of satisfaction with quality of health care will focus on structure, process and outcome. These three domains were fitted into SERVQUAL tool dimensions (tangible, reliability, responsiveness, assurance and empathy).

\section{Materials and Methods}

\section{Design and study area}

A cross-sectional study design was conducted at Mawenzi Referral Regional Hospital (MRRH), Same District Hospital (DH) and Huruma Designated District Hospital (DDH) in Kilimanjaro region from May to November 2015. Mawenzi is the referral regional hospital located in Moshi Municipality; Same DH is located in Same district, $100 \mathrm{~km}$ south-east of Moshi Municipality. Huruma DDH is in Rombo district council located in the north-eastern part of Kilimanjaro Region. Moshi and Same are urban districts while Rombo is a rural district. During the study period, the selected hospitals had more than 450 patients per day attending the OPD.

\section{Study population}

The study population consisted of patients who gave their consent and parents or caretakers of sick children who attended outpatient departments of the three selected hospitals during the study period. Critically ill patients, re-attendance of patients during study period, patients under 18 years olds without parents/care takers and admitted or discharged patients on the day of interview were excluded.

\section{Sample size and sampling}

A single population proportion sample size determination formula was used with the following assumption: the patients' level of satisfaction in Kilimanjaro region is $50 \%$, margin error of $5 \%$, and non-response rate of $10 \%$ and the desired level of confidence interval at 95\% [14]. A minimum sample size of 422 was calculated but the sample size of 450 participants was recruited. Purposive sampling was used to select the area of study based on locality and ownership. Simple random technique was employed to select the first participant through drawing a piece of paper written YES among five pieces of papers in a box placed at a registry section. The rest of participants were selected by using a systematic sampling based on the projected daily attendance at OPD. To get the sampling interval, a formula $\mathrm{N} / \mathrm{n}$ was used whereby $\mathrm{N}=$ the total number of patients attending OPD per day and $n=$ the estimated sample size.

Anonymous, structured SERVIQUAL questionnaire was adapted and then adopted to address the study objectives [15]. The SERVIQUAL questionnaire is divided into five service dimensions (tangibles, reliability, responsiveness, assurance and empathy) to determine patients' level of satisfaction with the health care services provision. According to SERVIQUAL questionnaire, the questions to assess patients' level of satisfaction are in two categories: 1) expectation and 2) perception questions.

The questionnaire was developed in English with back-and-forth translated in Kiswahili, the local language in Tanzania. The SERVIQAUL questionnaire in Kiswahili was then piloted with a convenient sample of $n=30$ for validity and reliability. Minor adjustments were made based on the pilot testing.

\section{Data management and analysis}

The dependent variable in this study was patients' level of satisfaction and was assessed by asking the level to which they were satisfied by looking at the gap between patient's expectations versus perceptions in the structure and process domains using a five point Likert Scale questions (rating points on the scale). The independent variables in this study include: socio demographic characteristics (sex, age, religion, marital status, occupation, education level, health insurance status, place of residence, number of visits made to the facility and number of OPD stations visited); Structure domains which includes tangibles and assurance (e.g. physical facilities, equipment and drugs, appearance of personnel and facilities, confidence, competence, courtesy and credibility).

A process domain includes reliability, responsiveness and empathy (e.g. patient-provider relationship, waiting time, confidentialityand affordability of hospital services). There were several questions constructed in each SERVQUAL domain that were asked according to patient's expectations and perceptions. Expected response was: $1=$ very dissatisfied; $2=$ dissatisfied; $3=$ neutral; $4=$ satisfied and $5=$ very satisfied.

Data entry and analysis was performed by using SPSS version 20 . Descriptive statistics such as frequency, percentages, measure of central tendency (dispersion) for continuous variables was computed. Paired sample t-test was used to compare means of continuous variables (patient's expectations versus perceptions). Independent sample t-test was used to compare independent categorical variables with continuous dependent variables. For more than two categorical variables, the gap difference was tested using one-way analysis of variance (ANOVA) with Bonferroni post-hoc test. A p-value of less than $5 \%$ was considered statistically significant.

\section{Ethics approval and consent to participate}

This study was approved by the Kilimanjaro Christian Medical College Research Ethics and Review Committee (CRERC) with ethical clearance number 825 . Permission to conduct the study was sought from MRRH, Huruma DDH and Same DH. Both written and verbal consent was sought from patients at OPDs after they have fully been explained about the study objectives. Participants were also informed that participation in the study was on voluntary basis, and the refusal to participate would not change their hospital care. Participant identification numbers instead of names were used to ensure confidentiality and privacy. All interviews were conducted in a private place. Furthermore, participants also consented for the data to be published to ensure that the information provided improves health services delivery at the OPDs.

\section{Results}

A total of 450 patients participated in this study. Females were $70.2 \%$ with the mean $( \pm S D)$ age of $42.0 \pm 16.5$ years. A majority of 
Citation: Olomi GA, Mboya IB, Manongi RN (2017) Patients' Level of Satisfaction with the Health Care Services Received at Outpatient Departments in Kilimanjaro Region, Tanzania. J Pat Care 3: 124. doi: 10.4172/2573-4598.1000124

respondents (58.2\%) were younger than 45 years and were residing in rural areas (56.9\%). Most of the socio-demographic characteristics of patients were not statistically different except for place of residence $(\mathrm{p}=0.025)($ Table 1$)$.

Majority of patients were non-referral $(89.3 \%, \mathrm{n}=402)$ and had visited the hospital at least twice (70.4\%). Most of participants had health insurance coverage (64.2\%) and were attended using health insurance the day of interview (97.2\%). The differences between hospitals visited did not statistically differ except according to referral status $(\mathrm{p}=0.02)$ and insurance status $(\mathrm{p}=0.001)$ (Table 2$)$.

\section{Satisfaction with quality of health service provision by hospitals}

The overall patient's level of satisfaction with health service provision in all three hospitals was only $20 \%$. The gap in health service provision in all three hospitals was $-37.0( \pm 47.0)$ signifying overall dissatisfaction among patients in health service provision. In comparison between hospitals there was no significant difference between Mawenzi and Huruma $(\mathrm{p}=0.379)$ or same $(\mathrm{p}=0.152)$. A significant gap difference was demonstrated between Huruma and Same Hospitals ( $p, 0.002)$. A smaller gap in satisfaction with service provision at Huruma DDH was -28.0 and Same DH was -46.7 (Figure 1).

Demographic characteristics were compared with patients' level of satisfaction among the three hospitals visited.

In general, level of satisfaction in relation to socio-demographic characteristics of patients did not statistically differ between hospitals, except according to patient's age (mean gap difference -10.7, 95\% CI:
$-19.5,-1.9 ; \mathrm{P}=0.017$ ), place of residence (mean gap difference $11.5,95 \%$ CI: 2.7, 20.2; $\mathrm{P}=0.010$ ) and number of $\mathrm{OPD}$ stations visited (mean gap difference 12.6, 95\% CI: 3.3, 21.8; $\mathrm{P}=0.008$ ) (Table 3).

In all five service dimensions, namely, tangibles, reliability, responsiveness, assurance and empathy; patient's expectations were higher than patient's perceptions. The highest mean expectation score was recorded on Reliability (75.84) followed by Empathy (74.17). Lowest mean expectation score was recorded on Assurance (61.73). Empathy had the highest perception-expectation mean gap score (-7.8), followed by Reliability (-7.64) and then by Tangibles and Responsiveness with mean gap score of -7.61 each respectively (Table 4 ).

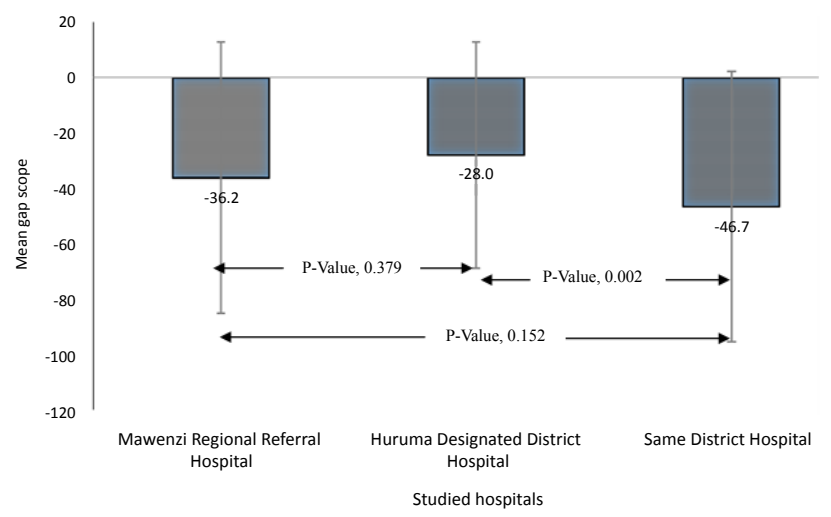

Figure 1: Comparison between the three hospitals on the gap in satisfaction with quality of service provision.

\begin{tabular}{|c|c|c|c|c|c|}
\hline \multirow{2}{*}{ Variable } & All $(n=450)$ & Mawenzi (n=150) & Huruma $(n=150)$ & Same $(n=150)$ & \multirow{2}{*}{ p-value } \\
\hline & No. (\%) & No. $(\%)$ & No. $(\%)$ & No. $(\%)$ & \\
\hline \multicolumn{6}{|l|}{ Sex } \\
\hline Male & $134(29.8)$ & $50(33.3)$ & $42(28.0)$ & $42(28.0)$ & \\
\hline Female & $316(70.2)$ & $100(66.7)$ & $108(72.0)$ & $108(72.0)$ & 0.507 \\
\hline \multicolumn{6}{|l|}{ Age (years) } \\
\hline Mean ( \pm SD, range) & $42.0( \pm 16.5,18-89)$ & $41.4( \pm 16.9,18-86)$ & $42.3( \pm 16.5,19-85)$ & $42.5( \pm 16.1,19-89)$ & 0.821 \\
\hline Younger than 30 & $131(29.1)$ & $48(32.0)$ & $43(28.7)$ & $40(26.7)$ & \\
\hline $30-44$ & $131(29.1)$ & $42(28.0)$ & $45(30.0)$ & $44(29.3)$ & \\
\hline $45-59$ & $104(23.1)$ & $33(22.0)$ & $33(22.0)$ & $38(25.3)$ & \\
\hline 60 or older & $84(18.7)$ & $27(18.0)$ & $29(19.3)$ & $28(18.7)$ & 0.965 \\
\hline \multicolumn{6}{|l|}{ Marital status } \\
\hline Married/cohabiting & $304(67.6)$ & $105(70.0)$ & $99(66.0)$ & $100(66.7)$ & \\
\hline Single & $94(20.9)$ & $30(20.0)$ & $32(21.3)$ & $32(21.3)$ & \\
\hline Widowed & $32(7.1)$ & $9(6.0)$ & $13(8.7)$ & $10(6.7)$ & \\
\hline Divorced/separated & $20(4.4)$ & $6(4.0)$ & $6(4.0)$ & $8(5.3)$ & 0.959 \\
\hline \multicolumn{6}{|l|}{ Highest education level } \\
\hline None & $34(7.6)$ & $6(4.0)$ & $14(9.3)$ & $14(9.3)$ & \\
\hline Primary & $262(58.2)$ & $94(62.7)$ & $85(56.7)$ & $83(55.3)$ & \\
\hline Secondary & $113(25.1)$ & $33(22.0)$ & $40(26.7)$ & $83(55.3)$ & \\
\hline Post-secondary & $41(9.1)$ & $17(11.3)$ & $11(7.3)$ & $13(8.7)$ & 0.341 \\
\hline \multicolumn{6}{|l|}{ Residence } \\
\hline Rural & $256(56.9)$ & $83(55.3)$ & $98(65.3)$ & $75(50.0)$ & \\
\hline Urban & $194(43.1)$ & $67(44.7)$ & $52(34.7)$ & $75(50.0)$ & 0.025 \\
\hline \multicolumn{6}{|l|}{ Occupation } \\
\hline Formal employment & $77(17.1)$ & $23(15.3)$ & $28(18.7)$ & $26(17.3)$ & \\
\hline Self-employment & $283(62.9)$ & $104(69.3)$ & $90(60.0)$ & $89(59.3)$ & \\
\hline Unemployed & $90(20.0)$ & $23(15.3)$ & $32(21.3)$ & $35(23.3)$ & 0.333 \\
\hline
\end{tabular}

Table 1: Social demographic characteristics of patients $(n=450)$. 
Citation: Olomi GA, Mboya IB, Manongi RN (2017) Patients' Level of Satisfaction with the Health Care Services Received at Outpatient Departments in Kilimanjaro Region, Tanzania. J Pat Care 3: 124. doi: 10.4172/2573-4598.1000124

Page 4 of 6

\begin{tabular}{|c|c|c|c|c|c|}
\hline \multirow{2}{*}{ Variable } & All $(n=450)$ & Mawenzi $(n=150)$ & Huruma $(n=150)$ & Same $(n=150)$ & p-value \\
\hline & No. $(\%)$ & No. $(\%)$ & No. $(\%)$ & No. $(\%)$ & \\
\hline \multicolumn{6}{|l|}{ Referral status } \\
\hline Referral & $48(10.7)$ & $17(11.3)$ & $25(16.7)$ & $6(4.0)$ & \\
\hline Non-referral & $402(89.3)$ & $133(88.7)$ & $125(83.3)$ & $144(96.0)$ & 0.002 \\
\hline \multicolumn{6}{|l|}{ Frequency of visits } \\
\hline First time & $67(14.9)$ & $33(22.0)$ & $17(11.3)$ & $17(11.3)$ & \\
\hline Twice & $66(14.7)$ & $21(14.0)$ & $22(14.7)$ & $23(15.3)$ & \\
\hline More than twice & $317(70.4)$ & $96(64.0)$ & $111(74.0)$ & $110(73.3)$ & 0.060 \\
\hline \multicolumn{6}{|l|}{ OPD stations visited } \\
\hline Medical records & $449(99.8)$ & 149 (99.3) & $150(100.0)$ & $150(100.0)$ & 0.367 \\
\hline Doctor's office & $448(99.6)$ & 149 (99.3) & 149 (99.3) & $150(100.0)$ & 0.605 \\
\hline Clinical laboratory & $148(32.9)$ & $46(30.7)$ & $52(34.7)$ & $50(33.3)$ & 0.754 \\
\hline Pharmacy & $395(87.8)$ & $128(85.3)$ & $130(86.7)$ & $137(91.3)$ & 0.250 \\
\hline Other stations & $24(5.3)$ & $9(6.0)$ & $3(2.0)$ & $12(8.0)$ & 0.062 \\
\hline Mean ( \pm SD, range) stations visited & $3( \pm 1,1-5)$ & $3( \pm 1,1-5)$ & $3( \pm 1,1-4)$ & $3( \pm 1,2-5)$ & \\
\hline \multicolumn{6}{|l|}{ Insurance status } \\
\hline Insured & $289(64.2)$ & $78(52.0)$ & $108(72.0)$ & $103(68.7)$ & \\
\hline Not insured & $161(35.8)$ & $72(48.0)$ & $42(28.0)$ & $47(31.3)$ & 0.001 \\
\hline Use of insurance & $n=289$ & $n=78$ & $n=108$ & $n=103$ & \\
\hline Used & $281(97.2)$ & $74(94.9)$ & $105(97.2)$ & $102(99.0)$ & \\
\hline Did not used & $8(2.8)$ & $4(5.1)$ & $3(2.8)$ & $1(1.0)$ & 0.240 \\
\hline
\end{tabular}

Table 2: Number (\%) of visit by hospital $(n=450)$.

\begin{tabular}{|c|c|c|c|c|c|}
\hline Variable & Total & Mean gap score (SD) & Mean gap difference. & $95 \% \mathrm{Cl}$ & p-value \\
\hline \multicolumn{6}{|l|}{ Gender } \\
\hline Male & 134 & $-34.5(46.2)$ & \multirow{2}{*}{3.5} & \multirow{2}{*}{$-6.0,13.1$} & \multirow{2}{*}{0.462} \\
\hline Female & 316 & $-38.0(47.4)$ & & & \\
\hline \multicolumn{6}{|l|}{ Age (years) } \\
\hline Younger than 45 & 262 & $-41.4(50.1)$ & \multirow{2}{*}{-10.7} & \multirow{2}{*}{$-19.5,-1.9$} & \multirow{2}{*}{0.017} \\
\hline 45 or older & 188 & $-30.7(41.7)$ & & & \\
\hline \multicolumn{6}{|l|}{ Education level } \\
\hline Up to primary & 296 & $-34.5(46.4)$ & \multirow{2}{*}{7.3} & \multirow{2}{*}{$-1.8,16.5$} & \multirow{2}{*}{0.117} \\
\hline Higher than primary & 154 & $-41.8(48.0)$ & & & \\
\hline \multicolumn{6}{|l|}{ Marital status } \\
\hline Never married & 94 & $-39.4(40.1)$ & \multirow{2}{*}{-3.1} & \multirow{2}{*}{$-13.8,7.6$} & \multirow{2}{*}{0.574} \\
\hline Ever married & 356 & $-36.3(48.7)$ & & & \\
\hline \multicolumn{6}{|l|}{ Place of residence } \\
\hline Rural & 256 & $-32.0(41.7)$ & \multirow{2}{*}{11.5} & \multirow{2}{*}{$2.7,20.2$} & \multirow{2}{*}{0.010} \\
\hline Urban & 194 & $-43.5(52.7)$ & & & \\
\hline \multicolumn{6}{|l|}{ Occupation } \\
\hline Formal employment & 77 & $-38.1(51.6)$ & \multirow{2}{*}{-1.4} & \multirow{2}{*}{$-12.9,10.2$} & \multirow{2}{*}{0.817} \\
\hline Non-formal employment & 373 & $-36.7(46.1)$ & & & \\
\hline \multicolumn{6}{|l|}{ Frequency of visits } \\
\hline First time & 67 & $-38.0(45.4)$ & \multirow{2}{*}{-1.2} & \multirow{2}{*}{$-13.4,11.1$} & \multirow{2}{*}{0.849} \\
\hline Not first time & 383 & $-36.8(47.4)$ & & & \\
\hline \multicolumn{6}{|l|}{ Referral status } \\
\hline Referred & 48 & $-25.5(51.7)$ & 120 & ח 127 & (2072 \\
\hline Not referred & 402 & $-38.3(46.3)$ & 12.9 & $-1.2,21.0$ & 0.073 \\
\hline Insurance status & & & & & \\
\hline Insured & 289 & $-37.3(43.4)$ & 0 & 10082 & 0851 \\
\hline Not insured & 161 & $-36.4(53.1)$ & -0.9 & $-10.0,0.2$ & 0.051 \\
\hline Insurance card use ( $n=289)$ & & & & & \\
\hline Used insurance & 281 & $-37.5(43.6)$ & -63 & -370243 & 0685 \\
\hline Did not use insurance & 8 & $-31.1(36.7)$ & & $-31.0,24.0$ & 0.000 \\
\hline Number of OPD stations visit & & & & & \\
\hline Less than 4 & 305 & $-32.9(44.5)$ & 126 & & (208 \\
\hline 4 or more & 145 & $-45.5(51.2)$ & 12.6 & $3.3,21.8$ & 0.008 \\
\hline
\end{tabular}

Table 3: Comparison of level of satisfaction according to socio-demographic characteristics of patients $(n=450)$. 


\begin{tabular}{|l|c|c|c|}
\hline Domain & $\begin{array}{c}\text { Perception mean } \\
\text { score }\end{array}$ & $\begin{array}{c}\text { Expectation mean } \\
\text { score }\end{array}$ & Mean gap score \\
\hline Tangibles & 56.54 & 64.15 & -7.61 \\
\hline Reliability & 68.20 & 75.84 & -7.64 \\
\hline Responsiveness & 59.18 & 66.79 & -7.61 \\
\hline Assurance & 55.41 & 61.73 & -6.32 \\
\hline Empathy & 66.37 & 74.17 & -7.8 \\
\hline
\end{tabular}

Table 4: Comparison of domains according to level of importance rating $(n=450)$.

\section{Discussion}

This study was conducted to determine patient's level of satisfaction with the health care services received at outpatient departments in Kilimanjaro Region, Tanzania. In general we found that patients were not satisfied with the services provided from the three hospitals (only $20 \%$ were satisfied). The overall gap in health service provision in all three hospitals was $-37.0( \pm 47.0)$, signifying overall dissatisfaction among patients with health services provision. This is in line with findings of patients' satisfaction studies elsewhere $[8,12]$. However, this is contrary to the study done in Thailand, whereby a higher proportion of patients were satisfied with quality of care [16]. This study revealed that patients' expectations were higher than their perceptions in all three hospitals whereby the lowest gap between patients' perception and expectations was found at Huruma DDH. This means patients were at least dissatisfied with the service provision compared to MRRH or Same $\mathrm{DH}$. The reasons for the difference could be due to ownership of these three hospitals. Huruma DDH is owned by a Faith-Based Organization that could be more committed, efficient and extends hospitality to patients in delivering a quality care as compared to Government hospitals. On the other hand, our findings are similar to that reported from another study which found that the satisfaction level was relatively low. Studies in Ghana and Thailand found that the overall patient's satisfaction level with quality of services delivered was good $[8,16,17]$. The reasons of these differences observed could be due to variations in the study area, sample size, hospital managements, different level of expectations among patients and the study populations.

Our study also found that some of patients' social demographic characteristics were important in determining their level of satisfaction. These included, patient's age, place of residence and number of OPD stations visited. The mean satisfaction levels with health care services provided at the outpatient departments was found to significantly differ by these characteristics.

Patients aged 45 years or younger were found to be more satisfied with the health services received than patients aged above 45 years. Similar findings have been reported elsewhere in Tanzania and Ethiopia [5,7,17]. The reasons could be due to level of patient's expectations that differed between these two groups and time spent during the process of care.

The patients' level of satisfaction was also found to significantly differ by place of residence. Most patients from rural areas than urban areas were comparatively satisfied. This could be due to geographical location of these three hospitals, lack of awareness and presence of few alternative hospitals in rural areas. It is also more likely that patients living in rural areas are less aware with their rights on quality of care, and others may failed to differentiate the hospitals providing quality care with the one providing poor care because they are not exposed to such environment of providing quality care. This was similar with findings from the study conducted in Ethiopia [5].

In this study, patients across the hospitals, who reported to visit less than four OPD sections, were more satisfied with the health care services provided than those who visited four or more sections. This may lead to the increased level of patient satisfaction because those who visited more OPD sections may spend more time or they may be required to return back to the diagnosing doctors leading to patients' dissatisfaction.

Gap score, which is a discrepancy between patient's expectation and perception about the dimensions of service quality among all four OPD sections in all three hospitals, revealed that dissatisfaction (negative mean gap) existed in all dimensions. The negative gaps that occurred for all dimensions indicated that patients' expectations generally were not met in all three hospitals.

These findings suggest that, there is more room for all three hospitals to improve service quality in relation to all dimensions because all them had higher patient's expectations than perceptions. These results are similar to the study done in Southern Iran [12]. However, a study in Ethiopia found that patients' were not satisfied with the service quality provision on tangibility and empathy domains [5]. Another study in Tanzania and Ghana observed negative gaps with regard to reliability, assurance and responsiveness but not on tangibility and empathy where they had positive dimension $[8,13]$. In contrast, only one study in Thailand has reported all five dimensions to have positive gaps [16].

Despite the relevance and applicability of the information obtained in this study, our findings are likely to have some limitations. The study failed to get subjective feelings of the participants about the situation on the ground. Information was obtained from the OPD patients who were available during the period of data collection only. This study did not also account for waiting time in registering and getting the hospital file. Time was recorded and accounted for after hospital files were obtained.

\section{Conclusion}

The results of this study in general showed that, patients' were not satisfied with the health care provision in all three hospitals. There were negative gaps between patient's perception and expectations on service quality provided by the three hospitals. So, to achieve the patients' expectations, the quality of health care services needs to be improved through improving patient-provider relationship, waiting time, appearance of physical facilities, availability of equipment and drugs and affordability of hospital bills.

A follow-up study is recommended to be conducted among health care providers on challenges they are facing in meeting patients expectations. Another study of patient satisfaction should include inpatients and outpatients using mixed methods.

\section{Acknowledgement}

The authors thank Pump Primming supported by Training Health Researchers into Vocational Excellence (THRiVE) in East Africa, grant number 087540, funded by Well come Trust for funding the study. Colleagues at Institute of Public Health at Kilimanjaro Christian Medical University Collage and all participants in this study.

\section{References}

1. Haddad S, Potvin L, Roberge D, Pineault R, Remondin M (2000) Patient perception of quality following visit to a doctor in primary care unit. BMC Fam Pract 17: 21-29.

2. Duong D, Binns C, Lee A, Hipgrave D (2004) Measuring client perceived quality of maternity service in rural Vietnam. Int J Qual Health Care 16: 447-452.

3. Jawahar SK, Kerala (2007) Study on out patient satisfaction at a super specialty hospital in India. Internet Journal of Medical Update 2: 13-17.

4. Ogunfowokan O, Mora M (2012) Time, expectation and satisfaction: Patients experience at National Hospital Abuja, Nigeria. Afr J Prim Health Care Fam Med 4: 398. 
Citation: Olomi GA, Mboya IB, Manongi RN (2017) Patients' Level of Satisfaction with the Health Care Services Received at Outpatient Departments in Kilimanjaro Region, Tanzania. J Pat Care 3: 124. doi: 10.4172/2573-4598.1000124

Page 6 of 6

5. Assefa F, Moses A, Johannes M (2011) Assessment of client's satisfaction with health service delivered at Jimma University specialized hospital. Ethiop $J$ Health Sci 21: 101-109.

6. Muhondwa E, Leshabari M, Mwangu M, Mbembeti N, Ezekiel M (2008) Patient satisfaction at Muhimbili National Hospital in Dar Es salaam, Tanzania. East Africa J Public Health 5: 2.

7. Juma D, Manongi R (2009) User's perception of outpatient quality of care in Kilosa district hospital in central Tanzania. Tanzan J Health Res 11: 4.

8. Khamis K, Njau B (2014) Patients' level of satisfaction on quality of health care at Mwananyamala hospital in Dar es Salaam, Tanzania. BMC Health Serv Res 14: 400 .

9. World Health Organization (WHO) (2000) Better outpatient services are the key to health gains for the poor. World Health Organization, Geneva (WHO/47).

10. Ministry of Health (2005) Review of the State of Health in Tanzania 2004. Ministry of Health, Dares Salaam, pp: 21-23.

11. Anderson R, Camacho F, Rajesh B (2007) Willing to wait? The influence of patient waits time on satisfaction with primary care. BMC Health Serv Res 7: 31
12. Aghamolaei T, Eftekhaari TE, Rafati S, Kahnouji K, Ahangari S, et al. (2014) Service quality assessment of a referral hospital in southern Iran with SERVQUAL technique: Patients' perspective. BMC Health Serv Res 14: 322 .

13. Peprah AA and Atarah BA (2014) Assessing patient's satisfaction using SERVQUAL model: A case of Sunyani Regional Hospital, Ghana. IJBSR, p: 4.

14. Cochran W (1977) Sampling techniques. $3^{\text {rd }}$ Ed. New York. John Wiley and Sons.

15. Senel M, Senel B (2006) The effect of European Foundation for Quality Management (EFQM) excellence model application on the perceived service quality; An application in health care.

16. Yousapronpaiboon K \& Phondej W (2014) Measuring pharmacy service quality of public hospitals in Thailand. Proceedings of $9^{\text {th }}$ Annual London Business Research Conference.

17. Gab K, Rwebangila F (2011) Patients' satisfaction with health care service provided at HIV clinics at Amana and Muhimbili hospital in Dar es Salaam. Afr Health Sci 11: 60-66. 